\title{
Individual health-related quality of life and the regional allocation of medical services: Insights from a stochastic health frontier analysis.
}

\author{
Rouven E Haschka ${ }^{1 *}$, Helmut Herwartz ${ }^{2}$, Katharina Schley ${ }^{2}$ \\ ${ }^{1}$ Chair for Econometrics, University of Göttingen, Humboldtallee, 3, 37120, Germany \\ ${ }^{2}$ Institute of Statistics, University of Göttingen, Humboldtallee, 3, 37120, Germany
}

\begin{abstract}
Health care systems around the world face increasing budgetary pressures due to a growing number of cases and new and costly treatment options. Improving health-related quality of life while achieving cost-containment is the ultimate goal of an efficient provision of health care services. By means of a stochastic frontier analysis, we condition subjective individual healthrelated quality of life on individual characteristics, such as health-related behaviour and socioeconomic status and regional indicators, like the medical infrastructure and demographic and socio-economic profiles. Our results indicate a positive relationship between general outpatient care and individual well-being. However, regional misallocation of medical services relates to inferior outcomes of regional health care service provision which are likely to negatively affect health-related quality of life at the individual level.
\end{abstract}

Keywords: Health-related quality of life, Health production, Health efficiency, Stochastic frontier analysis, Oversupply of medical services, Regional misallocation.

Accepted on August 17, 2020

\section{Introduction}

Many health care systems around the world are suffering from cost pressures. Especially ageing populations, obesity and unhealthy lifestyles lead to demographic and social changes which are at risk to raise burdens of chronic diseases (e.g. cancer, cardiovascular diseases, diabetes). A larger number of patients with more co-morbidities and needs for intensified treatments affect the cost per patient and increase the pressures on health care budgets. Nowadays, health care expenditures grow faster than the gross domestic product (GDP) in most developed countries [1].

Seeing prevalent financial pressures and needs to handle more cases at constant budgets, the notion of so-called value based care $[2,3]$, hints explicitly at the importance of quality of care within the multidimensional space of health outcomes. As noted in Porter [3] improving well-being at the individual level promises 'true' cost-containment. In this context reorganising the provision of medical care could become an important means to achieve favourable systemic health outcomes. Put differently, restructuring the regional allocation of the medical infrastructure might enhance well-being at individual levels and thereby benefit the efficiency of health care systems. Specifically, an unequal regional distribution of, e.g., physicians is likely related to an inferior performance of health care services showing up in higher burdens of diseases and, thus, ultimately straining the capabilities of the health care system. Additionally, growing costs of medical treatments arise from the over-use and misuse of medical services which are likely to spur the uncertainty of medical [4,5]. As all medical decisions are made under uncertainty, understanding the triggers of insecurity of patients possibly benefits Health-Related Quality of Life (HRQoL) and thereby supports cost containment.
A voluminous literature has been studying the performance of health care service provision and allows a broad classification into three research areas, (i) the efficiency of particular health care providers [6-8], for hospitals [9,10], for nursing homes [11], for physician practices), (ii) cross-country comparisons of health care systems [12-15], and (iii) regional variations of health care outcomes (for the cases of the US and Germany [16-21]. In light of the multidimensional nature of individual health and well-being, the regional level of analysis appears most suitable to unravel the determinants of HRQoL and of the uncertainty behind the evaluation of individual well-being, as well as to separate socio-demographic and health systemic effects for this purpose. Yet, the structural determinants of individual HRQoL and the uncertainty attached to the assessment of well-being have received surprisingly little attention in the related literature. Nevertheless, to improve quality of care and achieve 'true' costcontainment in the sense of Porter [3], it is essential to integrate the patient's perspective in the analysis of the effectiveness of health care provision.

An improved understanding of the performance of health care services with high spatial resolution is particularly relevant for the case of Germany featuring strong regional variations in (i) quality of life, (ii) burdens of disease, and (iii) the availability of medical services and infrastructure. Against this background, we examine the determinants of individual HRQoL prevailing in Germany. While we account for individual characteristics, our main focus is on the effects of medical infrastructure and its utilisation by including regional information on medical service provision and demographic and socio-economic profiles. Our empirical model fits into the framework of the health production function of Grossman [22] which we quantify in terms of a Stochastic Frontier Analysis (SFA). As a particular merit of the modelling approach, our study provides new insights into 
the relationship of health systemic determinants and deviations from the health frontier and/or the uncertainty behind socalled SF-12 scores which have become a widely accepted tool for quantifying individual health outcomes [23]. The nonlinear SFA approach offers to capture the direct relationship of individual level variables such as health behaviour and individual HRQoL while at the same time indirectly measuring an effect of the availability of medical services on regional level on individual well-being through inefficiency as possible transmission channel. We combine individual-level panel data from the German Socio-Economic Panel (SOEP) with regional administrative information. In total, the data set consists of more than 45000 observations.

One might argue that the relationship between individual health and the availability of medical services is possibly ambiguous, as more health care infrastructure might be allocated to regions with poor overall health. This raises risks of biased estimation results due to reversed causality. We address the potentials of a bidirectional relationship of individual health and regional health systemic determinants within a preliminary analysis. By means of a Hausman-Test [24], we compare the estimation results of a Fixed Effects (FE) panel model and an Instrumental Variable (IV) estimation with heteroscedasticity-based instruments [25]. Based on the corresponding results, we conclude that potential endogeneity does not result in estimation biases.

To preview some results, we diagnose a positive effect of general outpatient care and average HRQoL. Overall, we find a strong connection between the regional misallocation of medical services, and an inferior performance of local health care systems which leads to weakened growth of or even reductions in HRQoL. Moreover, our findings reflect the supply-sensitivity of care meaning that physicians create their own demand based on the available services [26]. Furthermore, the results indicate that the uncertainty attached to the assessment of well-being differs according to the level of care. For instance, a higher supply of general outpatient services relates to a reduction in the uncertainty while an increase in the number of medical specialists likely leads to a rise in the uncertainty attached to individual HRQoL. Similar to results of related studies $[16,27,28]$, regional deprivation is negatively associated with individuals' well-being.

In the next section, we describe the stochastic health frontier model and introduce the data. A set of appendices provides a discussion of the spatial estimation strategy (Appendix A), a technical description of the density function of inefficiency and the moment conditions (Appendix B), a detailed description of the data (Appendix C), and a discussion of the parameter estimates attached to the individual characteristics (Appendix D).

\section{Methodology}

In this section, we provide the empirical strategy to assess the stochastic deviations from the health frontier. Furthermore, we describe the data and the determination of the variables. The general SFA model of health production

SFA has become a common approach for modelling potentials and inefficiencies in various contexts, like the production of goods and services in economic entities (e.g., farms, firms, and hospitals). Unlike data envelopment approaches treating any deviation from a production function to result from inefficiency [29], the parametric SFA model allows to distinguish between inefficiency and random deviations from efficient service provision.

To evaluate how the allocation of medical infrastructure and regional demographic and socio-economic characteristics govern inefficiencies in the provision of individual HRQoL, we estimate a Grossman-type health production model [22]. We follow Wang [30] in the parametrisation of a one-step SFA model including exogenous influences on deviations from the health frontier. Quantifying the production function and deviations from the efficient technology simultaneously, one avoids eventually invalid conclusions based on two-step approaches which process estimated first-step efficiency scores [31].

The German health care system is characterised by free provider choice. Hence, spatial externalities (spillover effects) might play an important role in the provision and utilisation of health care services. As a result of patients migrating across regional borders, the efficiency of service provision in a given region might be influenced by the medical infrastructure in neighbouring regions. Supposing that regional health care services and the demographic and socio-economic environment influence the efficiency of health production, our pooled SFA modell for HRQoL of individual $i$ at time $t$ and located in region $\mathrm{j}$ reads as

$y_{i t}=\boldsymbol{x}_{i t}^{\prime} \beta+\kappa_{t}+v_{i t}-u_{i t} \quad i=1, \ldots, N, t=1, \ldots, T$,

where

$v_{i t} \sim N\left(0, \omega^{2}\right)$ and $u_{i t} \sim N^{+}\left(\mu_{j t}, \sigma_{j t}^{2}\right), j=1, \ldots, J$.

Moreover, conditional moments of $u_{i t}$ are

$\mu_{j t}=\boldsymbol{z}_{j t} \delta+\boldsymbol{z}_{j t}^{* \prime} \vartheta+v_{t}$ and $\sigma_{j t}^{2}=\exp \left(\boldsymbol{z}_{j t}^{\prime} \gamma+\boldsymbol{z}_{j t}^{*^{\prime}} \varphi+\tau_{t}\right)$

In (1), yit is the natural logarithm of HRQoL and xit is a K-dimensional vector of individual characteristics. In (2), we assume that inefficiency mainly arises from medical service provision and demographic and socio-economic characteristics at the regional level. Accordingly, zjt is a R-dimensional vector of region specific variables capturing the medical infrastructure as well as demographic and socio-economic factors for region $\mathrm{j}$ in time t. To account for patient mobility, we introduce a spatial structure in the distribution of the efficiency scores. We consider $Z_{j t}^{*}=w_{j} Z_{t}$

Where $\mathrm{Zt}$ is a $\mathrm{J} \times \mathrm{R}$ matrix of $\mathrm{J}$ regions and $\mathrm{R}$ covariates for a specific period t. Formalising the connectivity of regions, wj is a region specific weighting row vector of size J. The vector $Z_{j t}^{*}$ is a vector of the spatially lagged variables for region $\mathrm{j}$ at time $\mathrm{t}$ and represents a weighted average of the neighbouring regions. To determine the networking between regions, we define the spatial weights based on an exponential decay function [35]. By means of this approach and in contrast to other neighbourhood criteria, like nearest neighbours or distance thresholds with clear cut-off points, all regions are connected and the interactions between regions shrink with distance (Appendix A).

Stochastic deviations from the production frontier are captured by vit and assumed to be normally distributed with mean zero 
and variance $\omega^{2}$. As proposed by Wang [30] the inefficiency term uit follows a truncated-normal distribution with mean and variance depending on exogenous variables. By assumption, the inefficiencies are identically distributed per region (i.e. truncated normal with mean $\mu_{j t}$ and variance $\sigma_{j t}^{2}$ ). The parameters $\kappa_{t}, v_{t}$ and $\tau_{t}$ denote fixed time effects. As a particular merit, the model specification in (1) to (3) allows non-monotonic covariate effects on deviations from the health frontier ${ }^{2}$. Moreover, the conditioning of the variance of inefficiency (2) on explanatory variables offers a structural view at the uncertainty attached to the assessment of well-being at the individual level. The model in (1)-(3) is estimated by means of maximum likelihood (ML) estimation.

\section{Data and variables}

Data are drawn from two sources: the SOEP (individual health data and other demographic and socio-economic characteristics) and the INKAR database (regional data). The SOEP [36] is a household panel study. Since 1984 the respondents answer an individual and a household questionnaire every year (for further information on the SOEP [37]. Since 2002 a batch of health-related questions has been included in the SOEP every second year, the 'SF-12v2 ${ }^{\mathrm{TM}}$ Health Survey' (SF-12, Andersen et al. [38]). Additional information on healthrelated behaviour, e.g. smoking, is available since 2004. We only include individuals aged over 18 who participated in at least three waves. Overall, the data set consists of more than 45000 observations $^{3}$ (Appendix C). We match the individual-level data with regional administrative data drawn from the INKAR database. Administered by the Federal Institute for Research on Building, Urban Affairs and Spatial Development ${ }^{4}$ the INKAR database provides infrastructure and other regional characteristics. We base the regional analysis on the so-called spatial planning units ('Raumordnungsregionen', $\mathrm{ROR}^{5}$ ).

\section{Individual health-related quality of life}

The SF-12 has become a widely used statistic to monitor health and measure HRQoL [18,23,39]. Based on twelve healthrelated questions classified into eight health concepts (e.g. physical functioning, pain, vitality, social functioning), the SF12 comprises two sub-scales (principal components) of physical (PCS) and mental health (MCS). Taking account of the complex nature of wellbeing by integrating several dimensions, the SF12 is more informative than self-reported health at ordinal Likert scales. As a further advantage in comparison with other health indicators, it also includes the mental dimension of well-being. Since objective measures of the health status (e.g., mortality) cannot adequately illustrate the burden of chronic diseases, subjective measures like the SF-12 have become increasingly important to measure HRQoL [38]. Similar to Eibich and Ziebarth [18], we take the average of the two sub-scales PCS and MCS to obtain an indicator of HRQoL. By construction, this average ranges between 0 and 100 with mean 50 and standard deviation 7 (Table 1). Figure 1 displays the regional distribution of the weighted average of the SF- $12^{6}$. A visual inspection reveals regional clustering. HRQoL does not substantially differ between East and West Germany as other health outcomes, like mortality figures typically do [40,41].

\section{Individual characteristics}

We base the choice of explanatory variables for the conditioning of HRQoL largely on the related literature [18,42], and distinguish four groups of variables that refer to health-related behaviour, health care utilisation and demographic and socioeconomic characteristics. Collecting indicators of healthrelated behaviour the first group includes the Body-Mass-Index $(\mathrm{BMI})^{7}$ and two dummy variables indicating if a person smokes (smoking) or follows a health conscious diet (healthy diet). A mean BMI of 26.6 indicates that the German population has a tendency towards being overweight (Table 1). About $25 \%$ of the observed individual smoke, while more than 55\% consider themselves to follow a healthy diet.

The second group of variables contains information on health care utilisation. The dummy variable hospital stay indicates if a person stayed in hospital in the previous year. We also include the number of doctor visits (doctor visits) during the three months previous to the interviews. A dummy variable which takes a value of unity if the person is privately insured (private health insurance) controls for the health insurance status ${ }^{8}$. Table-1 shows that $16.5 \%$ of the observed individuals stayed in hospital in the previous year and saw a physician about three to four times during the three months previous to the interview. Approximately $13 \%$ of the sampled individuals are privately insured such that members of private health insurances are slightly over represented [43].

The third group of variables consists of demographic factors. We consider age (age) in a continuous manner both in level and in quadratic terms. Further dummy variables account for gender (male $=1$ if the person is male), nationality (nationality $=1$ if the person has a nationality other than German) and marital status (married $=1$ if a person is married). The mean age in our sample is 55.12 years. About $40 \%$ of the observed individuals are male while $5 \%$ of the sample have a nationality other than German. A considerable fraction (67\%) of sampled individuals are married.

The fourth group of variables captures the socio-economic status of an individual. In particular, it contains household income (income) ${ }^{9}$. Similar to the 'German Mikrozensus', we distinguish four groups of educational achievements. The first category (edu1) refers to individuals with an educational achievement of up to lower secondary level $\left(\right.$ ISCED $\left.^{10}\right)$. The second category (edu2) contains all individuals with upper secondary education. The third category (edu3) comprises all individuals with vocational training and bachelor degree. Category 4 (edu4) consists of individuals with (higher) academic degrees (master degree, $\mathrm{PhD}$ or equivalent). Moreover, we account for an individual's labour market status by means of four dummy variables. The first category (not employed) includes all persons that are not employed. The second and third category cover individuals working part-time (part time) and full-time (full time), respectively. The last category (training) includes all individuals either in vocational training, (voluntary) military or community service.

\section{Regional characteristics}

To explain how the availability and allocation of medical services shapes the performance of regional health care services, 
Citation: Haschka RE, Herwartz H, Schley K. Individual health-related quality of life and the regional allocation of medical services: Insights from a stochastic health frontier analysis. J Public Health Policy Plann April 2020;4(4):41-56

Table 1. Descriptive statistics. The table documents descriptive statistics for 11082 individuals observed every other year from 2004 to 2014 in the upper panel (45054 observations), and for the 96 regions in the lower panel (576 observations). The second and third column document the pooled sample means and the unbiased pooled standard deviations, respectively. The last two columns show between and within standard deviations.

\begin{tabular}{|c|c|c|c|c|}
\hline Variable & Mean & SD & Between SD & Within SD \\
\hline Health outcome sf12 & 47.94 & 7.271 & 6.228 & 3.812 \\
\hline \multicolumn{5}{|c|}{ Individual characteristics $\left(\mathrm{x}_{\mathrm{it}}\right)$} \\
\hline \multicolumn{5}{|c|}{ Health-related behaviour } \\
\hline bmi & 26.60 & 4.763 & 4.545 & 1.370 \\
\hline smoking & 0.25 & 0.432 & 0.391 & 0.182 \\
\hline healthy diet & 0.56 & 0.497 & 0.385 & 0.318 \\
\hline \multicolumn{5}{|c|}{ Health care utilisation } \\
\hline hospital_stay & 0.17 & 0.374 & 0.214 & 0.305 \\
\hline doctor_visit & 3.62 & 4.185 & 2.792 & 3.094 \\
\hline private_health_insurance & 0.14 & 0.342 & 0.333 & 0.087 \\
\hline \multicolumn{5}{|c|}{ Demographic factors } \\
\hline age & 55.12 & 16.085 & 16.093 & 2.999 \\
\hline male & 0.43 & 0.495 & 0.495 & 0.000 \\
\hline nationality & 0.05 & 0.214 & 0.210 & 0.037 \\
\hline married & 0.67 & 0.470 & 0.439 & 0.176 \\
\hline \multicolumn{5}{|c|}{ Socio-economic factors } \\
\hline income & 1835.65 & 1096.470 & 998.643 & 462.123 \\
\hline not_employed & 0.50 & 0.500 & 0.444 & 0.232 \\
\hline part_time & 0.17 & 0.371 & 0.305 & 0.213 \\
\hline full_time & 0.33 & 0.470 & 0.422 & 0.215 \\
\hline training & 0.01 & 0.086 & 0.058 & 0.067 \\
\hline edu1 & 0.13 & 0.335 & 0.334 & 0.057 \\
\hline edu2 & 0.50 & 0.500 & 0.490 & 0.095 \\
\hline edu3 & 0.13 & 0.338 & 0.332 & 0.065 \\
\hline edu4 & 0.24 & 0.425 & 0.418 & 0.068 \\
\hline \multicolumn{5}{|c|}{ Regional variables $\left(z_{j t}\right)$} \\
\hline \multicolumn{5}{|c|}{ Medical infrastructure } \\
\hline gp & 50.88 & 6.839 & 6.438 & 2.384 \\
\hline spec & 108.42 & 25.953 & 24.732 & 8.197 \\
\hline beds & 61.37 & 10.860 & 10.531 & 2.828 \\
\hline \multicolumn{5}{|c|}{ Demographic and socio-economic characteristics } \\
\hline gdpp.c. & 28.91 & 7.609 & 7.070 & 2.888 \\
\hline education & 28.14 & 7.719 & 5.630 & 5.307 \\
\hline age65 & 20.46 & 1.950 & 1.706 & 0.958 \\
\hline female & 50.90 & 0.408 & 0.390 & 0.123 \\
\hline unemployment & 8.38 & 4.150 & 3.613 & 2.069 \\
\hline
\end{tabular}

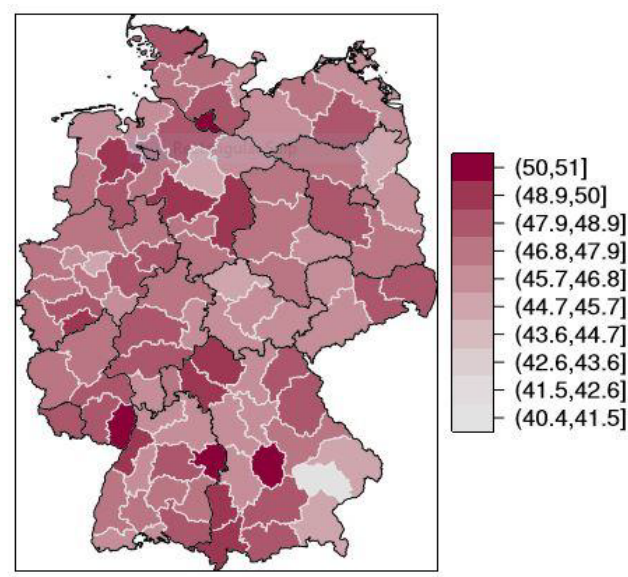

Figure 1. Spatial distribution of the weighted averages of the variable SF-12. 
we include regional information on medical service provision. A regional level analysis is of particular relevance as the provision of health care services is decided at regional levels. Further, empirical evidence for Germany $[18,44]$ suggests that potential sources of inefficiency are located at regional levels. Attributes of the health care infrastructure include the number of general practitioners (gp) and medical specialists (specialists) per 100,000 inhabitants and the number of hospital beds (beds) per 10,000 inhabitants. Figure 2 displays the regional distribution of the medical infrastructure. All graphs indicate regional clustering. The figure further displays a North-South gradient for general practitioners with higher densities in the South of Germany. Pointing to a rural-urban divide the graph reveals high densities of medical specialists in four major cities (for instance Berlin, Hamburg, Bremen and the area surrounding Munich).

As health is not only related to the health care system [45] and to refine the understanding of the underlying determinants of HRQoL, we also include regional information on demographic and socio-economic factors in the analysis $[18,27]$. Specifically, this group of explanatory variables consists of the gross domestic product (GDP) per capita (gdpp.c.), the share of school graduates with matriculation standard ('Hochschulreife') among all school graduates (education), the unemployment rate (unemployment) and the share of population older than 65 years (age 65).

\section{The efficiency of regional health provision}

In the following we discuss diagnostic and inferential results for the SFA model. Firstly, we consider the data based model selection. Secondly, we examine the regional variation of the performance of health care services. Thirdly, we discuss the extent to which the regional allocation of medical infrastructure and demographic and socio-economic characteristics shape the regional variation in the provision of health care services channelling into HRQoL divergence. If not mentioned otherwise, the discussion of estimation results refers to the nominal 5\% significance level.

\section{Model selection}

As Greene (2008) points out there is no theoretical guidance for the positioning of additional covariate information (the $\mathrm{z}$-variables) in the production function (1) or in the inefficiency term (3). Similar to Herwartz and Schley [44] we use a Vuong test [46] to determine a benchmark model specification.
Accordingly, we compare alternative model specifications with distinct positionings of the regional characteristics, gp, specialists, beds, gdpp.c, education, unemployment and age $65^{11}$. The test results are conclusive for the positioning of the variables gp, gdpp.c. and unemployment. For the other variables we select a most appropriate model specification by means of log-likelihood statistics. As a result of the model selection process, the medical infrastructure and the other indicators of regional heterogeneity are included in the specification of inefficiency in (3).

\section{Interaction of HRQoL and the availability of medical services}

One might argue that the relationship between the availability of medical services and the population well-being is potentially bidirectional. For example, physicians might sort into areas with an higher share of privately insured individuals which have a better health status. Similarly, regulators might allocate more resources to areas with less favourable health outcomes. Consequently, the regression results might suffer from endogeneity bias due to reversed causality. Pointing against such effects, however, it is noteworthy that the German health care sector is a highly regulated market which does not offer free access for physicians. Rather, the supply of health care infrastructure is externally determined by structural planning based on allocation formulas [47]. For example, the spatial planning of hospital beds is based on the so-called Hill-Burton-Formula which only implicitly takes morbidity into account. Additionally, it is noteworthy that we combine data on individual HRQoL with regional level administrative data on health care infrastructure which likely weakens potential endogeneity.

To further rule out the potential of regression biases, we test for endogeneity by means of a Hausman test. For this purpose, we condition individual HRQoL on individual health-related behaviour, the demographic, and socio-economic status and on regional-level information on the availability of medical services and socio-economic profiles. We estimate both a fixed effects (FE) and an instrumental variable (IV) panel model. In the IV regression, we treat three regional-level variables as possibly endogenous, in particular gp, specialists, and beds. The population density is a potential instrument which is not correlated with the dependent variable while it represents in some way structural planning activities. However, with three potentially endogenous variables and only one instrument, a general IV model is underidentified. Accordingly, we exploit the

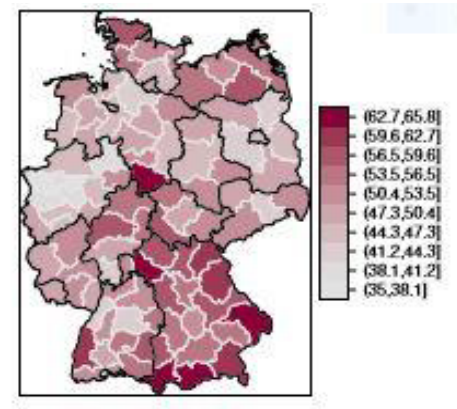

(a) General practicioners

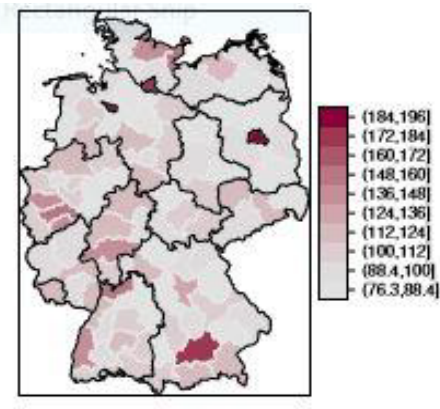

(b) Medical specialists

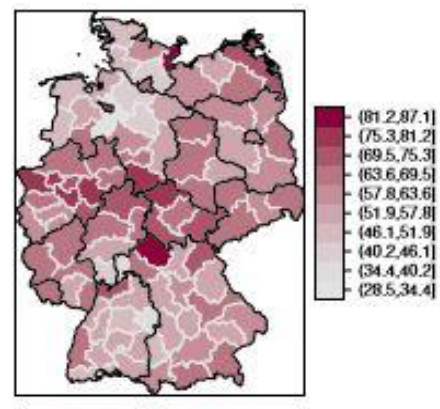

(c) Hospital beds

Figure 2. Spatial distribution of the medical infrastructure. 
informational content of heteroscedasticity-based instrumental variables [25], proposes an instrumental variable estimation which does not rely on external instruments. As Lewbel [25] argues, the efficiency of the IV estimation increases by including additional external instruments. Accordingly, we additionally include the population density as external instrument in the IV regression. Under the null hypothesis of the Hausman test, the differences in the coefficients between FE and IV regression are not systematic. Under the null hypothesis, the coefficients of both models are consistent while the FE-estimator is efficient. We conclude that our conditional model is sufficiently well specified based on a p-value of 0.8598. As it turns out from this exercise, potential endogeneity is unlikely to govern estimation biases in the documented results.

Table 2 documents the estimation result of the FE and IV model. The estimated coefficients of the individual level variables of both models are quite similar and have the expected sign except for the coefficient of age which lacks statistical significance. Potential multicollinearity might explain that the regional level variables lack statistical significance. This motivates the SFA approach taken in this study as it measures a direct effect of individual health behaviour on individual HRQoL while simultaneously assessing an indirect effect of the availability of health care services via inefficiency as transmission channel.

\section{Medical infrastructure and the inefficiency of regional service provision}

While we condition HRQoL on individual characteristics and health-related behaviour, our main focus is the role of the regional allocation of medical infrastructure and the utilisation of medical services. Our results for the parameter estimates attached to the individual-level variables (Appendix D andTable 6) largely resemble those found in the related literature $[24,48-50]^{12}$. Noticing that the model accounts for individual determinants of HRQoL with reasonable estimation results, the following discussion provides a complementary perspective on the determinants of HRQoL with a focus on health care service provision and utilisation. Firstly, we examine the regional patterns of health care performance. Secondly, we highlight the model implied relationships between systemic characteristics of health care in Germany and deviations from the health frontier ${ }^{13}$. As a particular merit of the modelling strategy, we accentuate in this context the role of system characteristics in shaping the uncertainty behind self assessments of HRQoL. Thirdly, we investigate the regional variation of the performance of health care services.

\section{Regional patterns of health care efficiency}

To get a first insight into the performance of regional health care systems and regional variation in HRQoL Figure 3 shows the distribution of the (sample weighted) mean estimated efficiency scores ${ }^{14}$. Apparently, in terms of HRQoL German regions do not perform at their full potential. The average efficiency level is 0.86 with a minimum of 0.76 and a maximum of 0.90 . An eyeball inspection of Figure 3 reveals regional clustering of efficiency scores.

\section{Marginal effects on expected HRQoL and the uncertainty of individual well-being}

By quantifying both mean and variance of the distribution of inefficiency the applied frontier model allows to detect possible determinants of expected HRQoL as well as uncertainty inherent in the individual assessment of well-being. In particular, we can emphasize nonmonotonic and non-linear relationships between the medical infrastructure and HRQoL. For this purpose, we calculate the individual marginal effects (7-8) (Appendix B). Subsequently, the regional (sample weighted) average marginal effects are classified and sorted by each variable into five groups. In this context, we firstly discuss the relationship between HRQoL and regional demographic and socio-economic characteristics. Secondly, we focus on the relationship between the medical infrastructure and HRQoL and the uncertainty attached to the individual evaluation of well-being. We compare intermediate estimation results systematically across categories by means of Analysis of Variance (ANOVA) techniques (Table 3).

HRQoL and regional diversity regarding the role of demographic and socio-economic regional characteristics and the deviations from the health frontier, the marginal effects assess

Table 2: Linear FE and IV regression (t-ratios in parentheses). All variables were within-transformed prior to estimation. The IV regression is based on a heteroscedasticity-based instrumental variable estimation (Lewbel, 2012).

\begin{tabular}{|c|c|c|}
\hline \multicolumn{3}{|c|}{ Health-related quality of life (SF-12) } \\
\hline & FE & IV \\
\hline \multicolumn{3}{|c|}{ Individual characteristics } \\
\hline Intercept & $-2.663(-1.59)$ & - \\
\hline bmi & $-0.039(-2.61)$ & $-.037(-2.53)$ \\
\hline hospital stay & $-1.055(-16.16)$ & $-1.056(16.17)$ \\
\hline doctor visit & $-.282(-44.00)$ & $-.282(-43.99)$ \\
\hline age & $0.008(0.25)$ & $-.006(-0.12)$ \\
\hline age $^{2}$ & $-0.002(-10.71)$ & $-.002(-10.67)$ \\
\hline In(income) & $0.427(4.19)$ & $0.413(4.03)$ \\
\hline \multicolumn{3}{|c|}{ Regional variables } \\
\hline gp & $-0.018(-1.17)$ & $-.076(-1.21)$ \\
\hline specialists & $-0.005(-1.19)$ & $-.028(-2.03)$ \\
\hline beds & $0.012(1.78)$ & $.027(1.26)$ \\
\hline $\ln ($ gdpp.c.) & $0.791(1.59)$ & $2.260(2.24)$ \\
\hline education & $-0.001(-0.22)$ & $0.002(0.30)$ \\
\hline age65 & $0.065(-1.52)$ & $0.037(0.81)$ \\
\hline unemployment & $-0.0007(-1.59)$ & $0.0009(0.04)$ \\
\hline
\end{tabular}




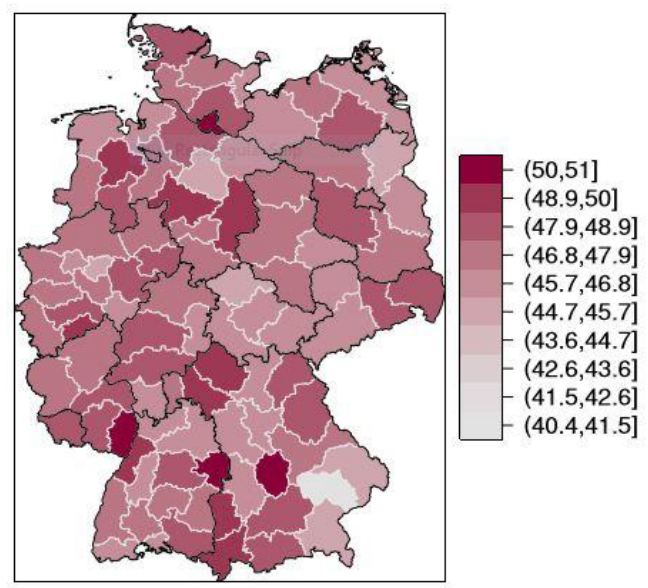

Figure 3. Spatial distribution for the average estimated technical efficiency scores implied by Model VI.

Table 3. Marginal effects on inefficiency. The table reports the marginal effects for the z-variables for Model VI. The data is sorted and classified into five groups by each z-variable. We classify the marginal effects of the spatially lagged variables by the level of the corresponding variable of the region. For the lowest, middle, and highest groups, the second and sixth columns report the mean of the respective variable, the third and sevenths columns show the average technical efficiency while the fourth, fifth, eighths and ninths columns report the marginal effect on E(uit) and $V(u i t)$, respectively. We test for significance in the mean effects of the classified regions with respect to the regions in the lowest quintile. The stars indicate $5 \%$ nominal significance.

\begin{tabular}{|c|c|c|c|c|c|c|c|c|}
\hline \multirow[t]{2}{*}{ Quintile } & \multirow{2}{*}{$\begin{array}{l}\text { Mean of } \\
\text { variable }\end{array}$} & \multirow{2}{*}{$\begin{array}{l}\text { Average } \\
\text { efficiency }\end{array}$} & \multicolumn{2}{|c|}{ Marginal effect } & \multirow{2}{*}{$\begin{array}{l}\text { Mean of } \\
\text { variable }\end{array}$} & \multirow{2}{*}{$\begin{array}{l}\text { Average } \\
\text { efficiency }\end{array}$} & \multicolumn{2}{|c|}{ Marginal effect } \\
\hline & & & on $E\left({ }^{u_{i t}}\right)$ & on $\operatorname{Var}\left({ }^{\mathrm{u}_{\mathrm{it}}}\right)$ & & & on $E\left(^{u_{i t}}\right)$ & on $\operatorname{Var}\left({ }^{\mathrm{u}_{\mathrm{it}}}\right)$ \\
\hline \multicolumn{9}{|c|}{ Medical infrastructure } \\
\hline & \multicolumn{4}{|c|}{$g p$} & \multicolumn{4}{|c|}{$\mathrm{gp}^{*}$} \\
\hline $1^{\text {st }}$ & 41.56 & .8536 & -.0402 & -.0061 & 41.56 & .8536 & .2201 & .0334 \\
\hline $3^{\text {rd }}$ & 50.66 & .8552 & -.0386 & -.0059 & 50.66 & .8552 & .2111 & .0319 \\
\hline \multirow[t]{2}{*}{$5^{\text {th }}$} & 60.80 & .8586 & $-.0352^{*}$ & $-.0056^{*}$ & 60.80 & .8586 & $.1916^{*}$ & $.0304^{*}$ \\
\hline & \multicolumn{4}{|c|}{ spec } & \multicolumn{4}{|c|}{ spec $^{*}$} \\
\hline $1^{\text {st }}$ & 80.52 & .8598 & -.0118 & .0029 & 80.52 & .8598 & .0457 & .0085 \\
\hline $3^{\text {rd }}$ & 104.18 & .8543 & $.0085^{*}$ & $.0059^{*}$ & 104.18 & .8543 & .0451 & $.0089^{*}$ \\
\hline \multirow[t]{2}{*}{$5^{\text {th }}$} & 149.55 & .8608 & $.0300^{*}$ & $.0092^{*}$ & 149.55 & .8608 & $.0433^{*}$ & $.0089^{*}$ \\
\hline & \multicolumn{4}{|c|}{ beds } & \multicolumn{3}{|c|}{ beds* } & \\
\hline $1^{\text {st }}$ & 46.10 & .8531 & .0086 & .0022 & 46.10 & .8531 & .1010 & .0170 \\
\hline $3^{\text {rd }}$ & 62.51 & .8563 & .0083 & .0022 & 62.51 & .8563 & .1051 & .0174 \\
\hline $5^{\text {th }}$ & 76.00 & .8507 & .0092 & $.0024^{*}$ & 76.00 & .8507 & .1014 & .0176 \\
\hline \multicolumn{9}{|c|}{ Demographic and socio-economic characteristics } \\
\hline & \multicolumn{4}{|c|}{ gdpp.c. } & \multicolumn{4}{|c|}{ age65 } \\
\hline $1^{\text {st }}$ & 20.11 & .8507 & -.0271 & -.0067 & 18.05 & .8639 & -.0042 & -.0010 \\
\hline $3^{\text {rd }}$ & 27.74 & .8600 & $-.0366^{*}$ & $-.0084^{*}$ & 20.34 & .8554 & $-.0031^{*}$ & $-.0008^{*}$ \\
\hline \multirow[t]{2}{*}{$5^{\text {th }}$} & 40.69 & .8572 & $-.0359^{*}$ & $-.0080^{*}$ & 23.41 & .8503 & $-.0017^{*}$ & $-.0006^{*}$ \\
\hline & \multicolumn{4}{|c|}{ education } & \multicolumn{4}{|c|}{ unemployment } \\
\hline $1^{\text {st }}$ & 18.61 & .8563 & -.0012 & -.0003 & 3.89 & .8513 & .0013 & .0002 \\
\hline $3^{\text {rd }}$ & 27.30 & .8589 & $-.0010^{*}$ & $-.0003^{*}$ & 7.65 & .8613 & $.0012^{*}$ & $.0001^{*}$ \\
\hline $5^{\text {th }}$ & 39.88 & .8554 & $-.0005^{*}$ & $-.0002^{*}$ & 15.13 & .8513 & $.0023^{*}$ & $.0003^{*}$ \\
\hline
\end{tabular}

how a change in the in the regional diversity relates, on average, to a change in the efficiency and performance of the health care provision. This can directly be translated into an average change in HRQoL at the individual level ${ }^{15}$. We diagnose a negative relationship between the performance of health care services and regional deprivation. Accordingly, higher regional per capita income (gdpp.c.) increases HRQoL. Low income families seem more likely confronted with access barriers to medical services [51,52]. Similarly, a larger proportion of graduates with matriculation standard (education) leads to an improved well-being. This result is intuitively appealing, since superior educational achievements are generally associated with an intensified utilisation of preventive care [53] and a strengthened awareness of medical treatments. Moreover, we diagnose a negative relationship between unemployment (unemployment) and HRQoL. On the one hand, this could possibly reflect a lower utilisation of medical services due to potential access barriers of the unemployed. On the other hand, unemployment is associated with economic hardship which might lead to reduced spending on health care and stronger burdens of disease [18,27,54-56]. Somewhat surprisingly, a larger share of the elderly (age 64) appears related with an improved performance of health care services in terms of HRQoL. Similar to our results, Eibich and Ziebarth [57] diagnose a direct positive association between the share of the elderly and the SF-12 for the German districts. They explain their result by the availability of possibly better health 
care resources in districts with a high share of the elderly and by the longevity of the population in general.

HRQoL and the medical infrastructure regarding the role of health systemic characteristics in explaining HRQoL, we diagnose a non-monotonic relationship between medical specialists (spec) and individual well-being. For example, in regions with a relatively low supply of specialists an increase of services translates into average improvements of HRQoL of $1.2 \%$. In regions with medium and relatively high supply an expansion in the provision of medical specialists indicates potential HRQoL losses of $0.9 \%$ and $3 \%$, respectively. This might hint at a potential oversupply of specialized care. The supply of specialized medical services in neighbouring regions $\left(\right.$ spec $\left.^{*}\right)$ shows adverse effects on local health outcomes. Hence, a sufficient local supply of specialized outpatient care seems advantageous for the efficient provision of health care services and results in an improved HRQoL especially in regions with a relatively low supply of specialized physicians.

Similar to the case of specialized health care, the marginal effects of an increased provision of general care (gp) appear nonlinear with stronger improvements of HRQoL in regions with a relatively low supply of general medical services and smaller gains in areas with a relatively high supply. The marginal benefits in HRQoL are about $4.0 \%, 3.8 \%$, and $3.5 \%$ for the regions with lowest, middle and highest density of general practitioners, respectively. The effect difference between the result for regions with lowest and medium density lacks significance, however. Medical services provided in neighbouring regions are associated with weakened performance of local health care services. Furthermore, the number of hospital beds (beds) has a negative effect on HRQoL. Similar to the results for medical specialists the size of the effect increases with the number of hospital beds. The differences in the mean effects, however, lack statistical significance.

Seeing that marginal effects of medical service provision depend in a non-monotonic manner on the medical infrastructure is generally in line with the notion of supply-sensitive care, stating that the utilisation of medical resources mainly reflects their supply [58]. In other words, physicians are supposed to create their own demand based on the available resources [26]. As an implication, more health care services and/or expenditures do not necessarily lead to improvements of HRQoL $[58,59]^{17}$.

The uncertainty of HRQoL Besides promoting health, health care systems could support patients by targeting the uncertainty attached to medical decision making. Uncertainty about individual HRQoL possibly results in an over-use of costly services and redundant medical treatments (McNeil, 2001). From a patients perspective, a reduction in the uncertainty of medical decision making would possibly reduce the level of stress emerging from unsettled times of illness [60-68] translating into an improvement of HRQoL. Our results offer new insights into the determinants of uncertainty. We find that the uncertainty attached to the evaluation of well-being differs according to the existing supply of medical services similar to the marginal effects on expected HRQoL. In particular, a growing supply of general medical outpatient services likely decreases the variation of HRQoL. The possible reduction in the variation of HRQoL in regions with a low supply is more pronounced as opposed to regions with a relatively high level of services. This further highlights possible positive effects of a sufficient local supply of general outpatient care [69-75]. In contrast to this, a higher supply of medical specialists increases on average the uncertainty in the assessment of well-being. This relationship is less pronounced in regions with a relatively low level of specialized care which implies a potential oversupply of specialized medical services in some regions.

In particular, a lack of coordination between service providers likely raises the uncertainty of medical decision making of patients [76-81]. Further, the direct access to medical specialists possibly increases the uncertainty attached to the considerations of treatment options. This is especially relevant for regions with a high level of supply as low access barriers to medical care facilitate the utilisation of services.

\section{Second-stage results of marginal effects and efficiency levels}

Medical service provision and utilisation in East and West Germany To gain further insights into the relationship between medical infrastructure and HRQoL, we classify the German regions according to morbidity profiles ${ }^{3}$. Subsequently, we analyse differences in the marginal effects.

In Table 4, we compare the marginal effects in West German regions with a high morbidity profile with regions in West Germany with a low morbidity profile and regions in East Germany ${ }^{18}$. Interestingly, we do not find significant differences between the average marginal effects in West Germany. This result potentially suggests that regional patterns in the provision and utilisation of medical services do not sufficiently explain morbidity differentials in West German regions. Accordingly, we concentrate the subsequent discussion on the differences between East and West German regions with a high morbidity profile. For general outpatient care, a higher level of medical services translates into a potential average HRQoL improvement of 5.7\% in Eastern and 3.3\% in Western regions. Furthermore, regions in East Germany would likely benefit from a higher supply of specialized care (average benefit in HRQoL of 3.8\%) while the opposite holds for the regions in West Germany. On the one hand, this hints at a potential misallocation of the medical infrastructure. On the other hand, the more pronounced beneficiary effects on efficiency and HRQoL in Eastern regions indicate that East Germany benefited from structural investments in health care infrastructure leading to a more efficient service provision [40]. The medical infrastructure in the neighbouring regions relates to higher potential output losses in East Germany. This finding additionally emphasizes the importance of a reallocation of medical services especially for the case of regions in Eastern Germany.

With respect to regional deprivation, we find smaller potential benefits of higher income and better education in Eastern regions. Moreover, the relationship between unemployment and HRQoL is more pronounced in East Germany. These results highlight differences in the utilisation patterns between East and West Germany still prevailing almost three decades after the German reunification. 
Table 4. Average marginal effects on inefficiency according to morbidity profiles. The second and third columns show the average marginal effects on E(uit) for the West German regions with high and low morbidity profiles, respectively. The fourth column reports the average marginal effects for the East German regions (all regions have a morbidity profile above the German average). The three rightmost columns document the average marginal effects on $V$ (uit) for regions in West (high and low mortality) and East Germany, respectively. We test for significance in the mean of the groups with respect to the West German districts with high morbidity. The stars indicate $5 \%$ nominal significance.

\begin{tabular}{|c|c|c|c|c|c|c|}
\hline \multirow[t]{3}{*}{ Variable } & \multicolumn{3}{|c|}{ Marginal effect on $E\left(u_{i t}\right)$} & \multicolumn{3}{|c|}{ Marginal effect on $\operatorname{Var}\left(\mathrm{u}_{\mathrm{it}}\right)$} \\
\hline & \multicolumn{2}{|c|}{ West } & \multirow[t]{2}{*}{ East } & \multicolumn{2}{|c|}{ West } & \multirow[t]{2}{*}{ East } \\
\hline & high & low & & high & low & \\
\hline \multicolumn{7}{|c|}{ Medical infrastructure } \\
\hline $\ln (g p)$ & -.0329 & -.0328 & $-.0572^{*}$ & -.0053 & -.0052 & $-.0080^{*}$ \\
\hline In(specialists) & .0187 & .0178 & $-.0376^{*}$ & .0073 & .0071 & $-.0001^{*}$ \\
\hline In(beds) & .0105 & .0103 & $.0041^{*}$ & .0026 & .0025 & $.0016^{*}$ \\
\hline $\ln (g p *)$ & .1789 & .1782 & $.3147^{*}$ & .0289 & 0.0283 & $.0440^{*}$ \\
\hline In(specialists $*$ ) & .0444 & .0439 & $.0488^{*}$ & .0090 & $.0087^{*}$ & .0090 \\
\hline $\ln ($ beds $*)$ & .0912 & .0906 & $.1347^{*}$ & .0163 & .0160 & $.0207^{*}$ \\
\hline \multicolumn{7}{|c|}{ Demographic and socio-economic characteristics } \\
\hline $\ln ($ gdpp.c.) & -.0370 & -.0364 & $-.0245^{*}$ & -.0085 & -.0082 & $-.0064^{*}$ \\
\hline education & -.0011 & -.0011 & $-.0002^{*}$ & -.0003 & -.0003 & $-.0002^{*}$ \\
\hline age65 & -.0038 & -.0037 & $-.0010^{*}$ & -.0010 & -.0009 & $-.0005^{*}$ \\
\hline unemployment & .0011 & .0012 & $.0026^{\star}$ & .0001 & .0001 & $.0003^{*}$ \\
\hline
\end{tabular}

\section{Conclusion}

Health care systems around the world face growing financial pressures to satisfy the demands of an ageing population with a rise in the burden of chronic diseases. Nowadays, health care expenditures grow faster than GDP in most developed economies.

To meet financial pressures service providers need to handle more cases while the budgets remain largely stable. Under the notion of value-based care, the health care literature has intensively discussed possible solutions to cost-containment including the improvement of quality of care. The regional reorganisation of medical infrastructure is an important means to promote the performance of health care service provision translating into enhanced HRQoL.

We analyse how the availability of health care services shapes HRQoL for the case of German regions by means of a health production function approach. For a model including spatial health care utilisation patterns, the estimation results unravel a positive relationship between general outpatient care and HRQoL. Nevertheless, regional misallocation of medical services in general leads to a potential reduction of individual well-being. Pointing at supply-sensitive care in Germany, the relationship between the provision of medical services and HRQoL seems to be sensitive to the level of the local supply. For instance, the beneficial effects of medical care on HRQoL are more pronounced in areas with a low supply of medical services. Both regional utilisation patterns of and the access to health care services influence HRQoL. In particular, regional deprivation negatively affects HRQoL. Furthermore, we find that the uncertainty attached to the evaluation of HRQoL at the individual level differs according to the level of care. For instance, a higher supply of general practitioners reduces the uncertainty while a higher number of medical specialists increase it.

Out findings have several important policy implications: First, to improve the performance of regional health care services in Germany and to reduce inefficiencies, the resource allocation of medical infrastructure should take account of the supplysensitivity of medical care. Second, taking patient mobility across regional borders into account, our results highlight the importance of a sufficient local supply of general outpatient care. In this context, strategies to promote the utilisation of local general medical services could improve the performance of regional health care services. A possible solution might be to emphasize general practitioners as gatekeepers, which has been discussed in different contexts. Third, the regional planning of medical infrastructure should additionally include regional socio-economic factors to promote the performance of health care services.

\section{Appendix}

\section{A Spatial cross-regressive model}

As already pointed out, patients in Germany may choose a medical service provider according to their own preference. Accordingly, spatial externalities might play a role in the provision and utilisation of health care services. To control for those spatial spillover effects, we include spatially lagged variables in the specification of the conditional moments of inefficiency (3). This approach is closely related to a so called spatial cross-regressive model as introduced by Florax and Folmer, which is an extension of a simple linear model and accounts for spatial dependencies by incorporating exogenous lagged variables. The spatial crossregressive model reads as

$$
y=X \beta+W \tilde{X} \rho+\varepsilon
$$

Where $\mathrm{y}$ is a row vector of size $\mathrm{M}$ of the dependent variable, $\mathrm{X}$ is a $\mathrm{M} \times \mathrm{k}$ matrix of explanatory variables, is a $\mathrm{M} \times(\mathrm{k}-1)$ matrix of regressors without constant, and is a stochastic disturbance term with mean zero and constant variance. In (5), let $\mathrm{W}$ be a $\mathrm{M}$ $\times$ M spatial weights matrix formalising the connectivity among region. By assumption the diagonal elements are equal to zero [60]. The spatial weights matrix is row standardized.

In our application, $\mathrm{J}=\mathrm{M}$ and $\mathrm{wj}$ in (4) refers to the jth row of $\mathrm{W}$. We base the connectivity among districts on an exponential decay function. By means of this approach, all regions are 
Citation: Haschka RE, Herwartz H, Schley K. Individual health-related quality of life and the regional allocation of medical services: Insights from a stochastic health frontier analysis. J Public Health Policy Plann April 2020;4(4):41-56

connected while the rate of interactions decreases with distance. Accordingly, the interconnectivity between region $\mathrm{j}$ and its neighbour 1 for a given distance djl is

$$
w_{j l}=\exp \left(-\alpha d_{j l}\right)
$$

where wjl is the element in row $\mathrm{j}$ and column 1 of matrix $\mathrm{W}$, $\alpha$ is the rate of decay and determines the inflection point of the curve [35]. The distance between the population weighted centroids of region $\mathrm{j}$ and region 1 is $\mathrm{d} j \mathrm{jl}$. An advantage of using the populations weighted centroids as opposed to the geographic centroids is that in large rural regions the centroid of economic activity may differ from the geographic centroid. Figure 4 illustrates the differences between the geographic (red) and population-weighted centroids (black). With reference to a result of Raknes et al. [64] we set the rate of the exponential decay function to correspond to $50 \mathrm{~km}$.

\section{$B \quad$ Moments of inefficiency and marginal effects}

For a SFA model where the inefficiency follows a truncated normal distribution according to (2), the conditional density $\mathrm{f}(\mathrm{u} \mid \varepsilon)$, where $\varepsilon=\mathrm{v}-\mathrm{u}$ is

$$
f(u \mid \varepsilon)=\frac{1}{\sqrt{2 \pi} \sigma_{*} \phi\left(\frac{\mu_{*}}{\sigma_{*}}\right)} \exp \left[-\frac{1}{2}\left(\frac{u-\mu_{*}}{\sigma_{*}}\right)^{2}\right]
$$

where $\mu *$ and $\sigma *$ are respectively

$$
\mu_{*}=\frac{\mu \sigma_{v}^{2}-\varepsilon \sigma_{u}^{2}}{\sigma_{v}^{2}+\sigma_{u}^{2}} \text {, and } \sigma_{*}=\frac{\sigma_{v}^{2} \sigma_{u}^{2}}{\sigma_{v}^{2}+\sigma_{u}^{2}}
$$

Following Wang (2002), the unconditional mean and variance of uit are

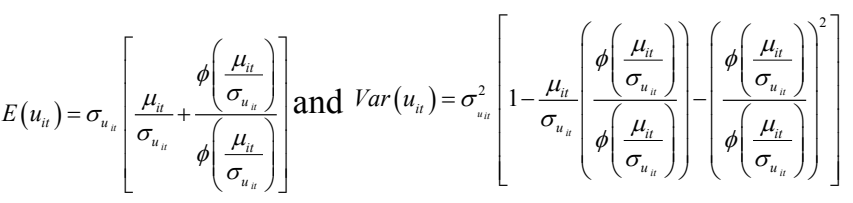

The main focus of this analysis is to answer the question how misallocation of medical infrastructure governs (in-) efficiencies in the production on health. Due to the non-linear relationship between the expected inefficiency and the variables in $z$, the ML estimates of (3) may not be fully interpretive. Simply, the direction of the estimate can be interpreted. Further, zit may have non-monotonic effects on efficiency. Following Wang [30], the marginal effect of $\mathrm{zr}$ on E(uit), where $\mathrm{zr}$ relates to the $\mathrm{r}$-th variable in the R-dimensional vector zjt in (3), reads as

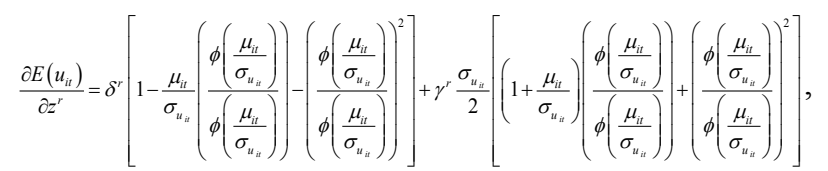

In (7) $\varphi$ and $\Phi$ are the probability and cumulative density function of a standard normal distribution, respectively. The parameters $\delta \mathrm{r}$ and $\gamma \mathrm{r}$ are the corresponding coefficients of (3).

The marginal effect of zr on $\operatorname{Var}($ uit) is

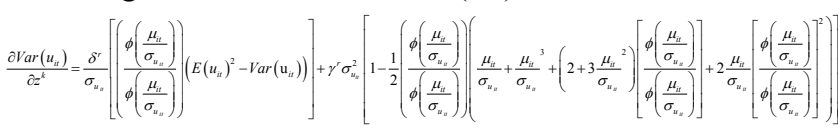

\section{Data description}

C.1 Individual data As primary source for our data we use the SOEP database wave 31 (SOEP V.31). The SOEP database already provides most of the data in a panel long format (wave 311). We use the following databases: hgen, hl, pl, ppfadl, pequiv, pgen, health, kreise 1, and ror long. See Table 4 for an overview of the variables used.

C.2 Regional variables Health care infrastructure The INKAR database provides the annual data on the number of physicians and general practitioners based on the registry of the National Association of Statutory Health Insurance Physicians ('Ärzteregister der Kassenärztlichen Bundesvereinigung'). We base the analysis on publicly funded resident physicians, as data on private physicians is not available at the regional level. We

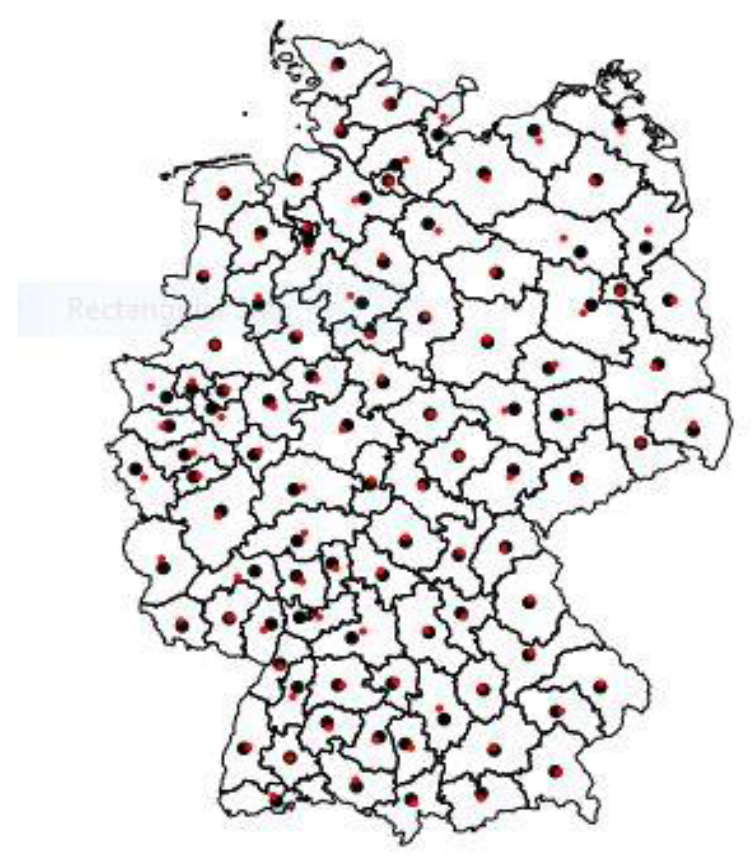

Figure 4. Regional centroids. The figure illustrates the differences between the geographic (red) and population-weighted centroids (black) for the RORs in Germany. 
calculate the number of medical specialists as the difference between the total number of physicians and the number of general practitioners. The number of hospital beds is based on the hospital statistics ('Krankenhausstatistik des Bundes und der Länder') and also available at INKAR.

Socio-economic and demographic characteristics. The data on socio-economic and demographic factors are drawn from the INKAR database. We use the gross domestic product per capita to account for income in 1,000 Euros. Education is the share of school graduated with matriculation standard ('Hochschulreife') in all school leavers. The unemployment rate is the share of unemployed in the labour force as calculated by the Federal Employment Agency ('Bundesagentur für Arbeit'). The share of 65 years old is the proportion of inhabitants older than 65 years in all inhabitants (Table 5).

\section{$D$}

\section{Estimated elasticities of HRQoL}

As the model in (1)-(3) appropriately explains the individual determinants of HRQoL, we have focussed the discussion of the empirical results above on the relationship between health care service provision and well-being at individual levels. In the following, we provide a discussion of the estimates attached to the individual characteristics (like health-related behaviour and socio-economic status). All parameter estimates are statistically significant except for nationality, married, not employed and training (Table 6).

It is well known that obesity is a trigger of many chronic diseases [63]. Accordingly, HRQoL improves with weight loss. Our results are in line with this common reasoning and show that a higher BMI is associated with reduced HRQoL. Okosun et al. [50] find a similar relationship for obesity and self-related health of US-American adults. Similarly, we find a negative association between smoking and individual well-being as smoking induces a high risk of death and disability [49]. Additionally, following a health concious diet is, on average, correlated with an improved HRQoL.

The utilisation of health care services negatively relates to HRQoL. Confirming similar findings [64], being privately insured seems to improve the respondents' HRQoL while controlling for household income. The relationship between age and HRQoL is quadratic. In younger years, becoming older likely enhances well-being. Starting at a certain threshold an increasing age is associated with a lower HRQoL. This result is intuitively appealing, as the burden of disease increases with age. Male individuals appear to feel healthier in comparison with females. This highlights biological and behavioural sex differences beyond the child bearing years $[57,65]$. Women tend to a higher utilisation of services $[65,66]$. The negative, though insignificant parameter estimate of nationality could indicate access barriers to the health care system for immigrants [51,52]. Moreover, we diagnose that married individuals are with $10 \%$ significance healthier in comparison with the unmarried. This might firstly capture a direct beneficial effect of marriage on quality of life (so called marriage protection effect). Secondly, it could illustrate a so called marriage selection effect as healthier individuals are more likely to get married [67].

Regarding an individuals' socio-economic status, a higher household income promotes HRQoL. Similarly, the negative parameter estimates attached to the education dummies indicate that a higher level of education benefits HRQoL. Both results are intuitively appealing, as higher income and education likely lead to a healthier lifestyle, more frequent utilisation of services

Table 5: Variable summary. The first columns gives the variable used in the analysis. The second and third column show the variable as given in the SOEP data set and a description of its calculation.

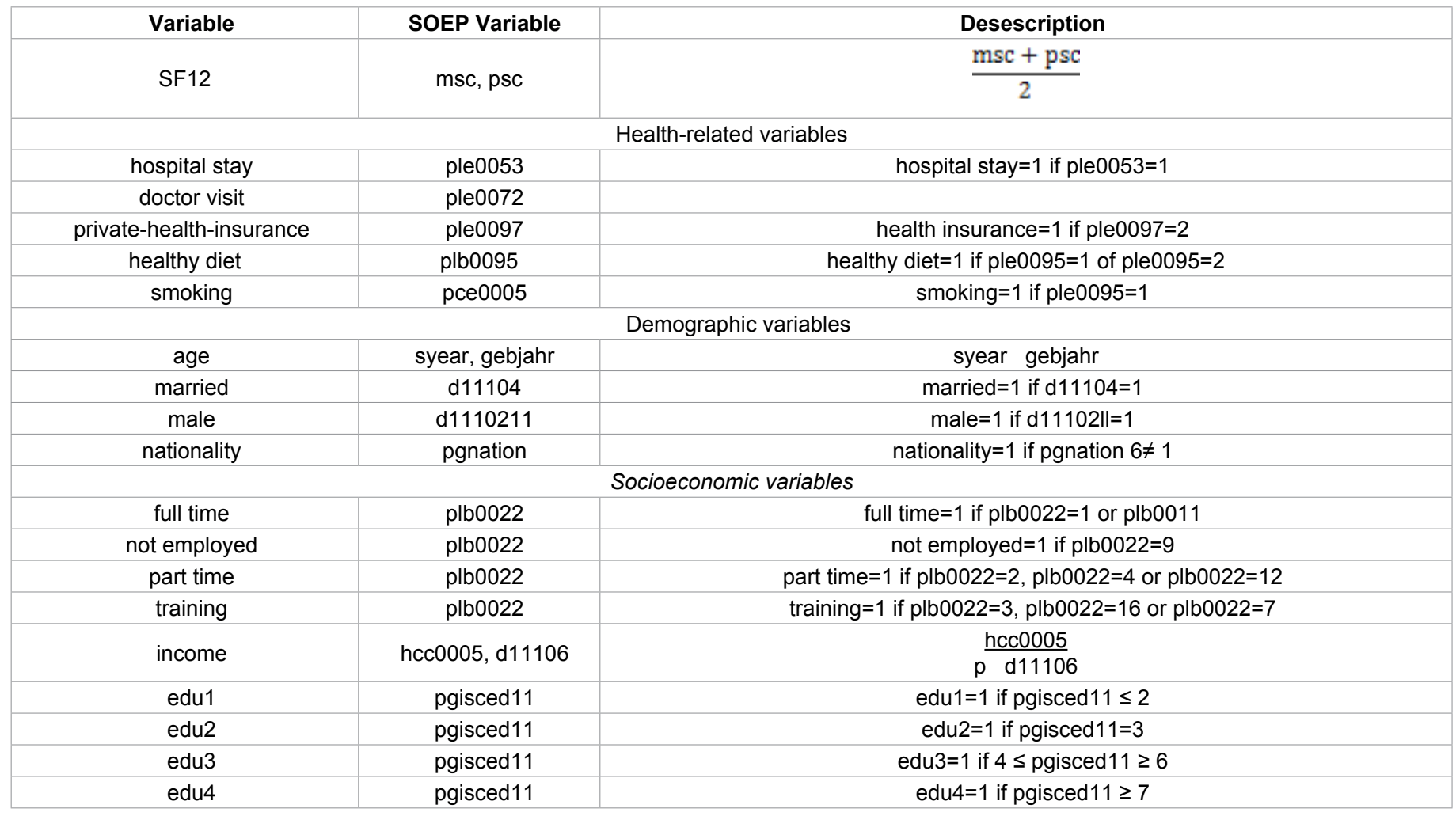


Citation: Haschka RE, Herwartz H, Schley K. Individual health-related quality of life and the regional allocation of medical services: Insights from a stochastic health frontier analysis. J Public Health Policy Plann April 2020;4(4):41-56

Table 6. SFA regressions (t-ratios in parentheses). The table documents the regression results of the relationship between individual HRQoL, individual socio-demographic and economic, health-related behaviour and regional characteristics of provision and utilisation of health care services at ROR-level.

\begin{tabular}{|c|c|c|c|}
\hline \multicolumn{4}{|c|}{ Health-related quality of life (In(SF-12)) } \\
\hline \multicolumn{2}{|c|}{ Individual characteristics $\left(\mathrm{x}_{\mathrm{it}}\right)$} & \multirow{2}{*}{\multicolumn{2}{|c|}{$\begin{array}{l}\text { Regional effects on inefficiency }\left(\mathrm{z}_{\mathrm{jt}}\right) \\
\text { Exogenous inefficiency determinants }\end{array}$}} \\
\hline & & & \\
\hline Intercept & $3.955(53.3)$ & Intercept & $-5.452(-0.94)$ \\
\hline $\ln (\mathrm{bmi})$ & $-0.054(-15.7)$ & $\ln (g p)$ & $-0.247(-1.96)$ \\
\hline smoke & $-0.016(-12.08)$ & In(specialists) & $-0.495(-4.5)$ \\
\hline healthy diet & $0.015(13.15)$ & In(beds) & $-0.050(-0.53)$ \\
\hline hospital stay & $-0.028(-18.59)$ & $\ln \left(\mathrm{gp}^{*}\right)$ & $1.373(2.74)$ \\
\hline $\ln ($ doctor visit) & $-0.050(-59.85)$ & In(specialists*) & $0.076(0.12)$ \\
\hline Private_health_insurance & $0.008(5.05)$ & $\ln \left(\right.$ beds $\left.^{*}\right)$ & $0.467(1.10)$ \\
\hline $\ln ($ age $)$ & $0.115(2.95)$ & In(gdpp.c.) & $0.084(0.76)$ \\
\hline $\ln \left(\operatorname{age}^{2}\right)$ & $-0.024(-4.75)$ & education & $0.007(4.12)$ \\
\hline male & $0.019(15.5)$ & age65 & $0.022(2.91)$ \\
\hline nationality & $-0.003(-1.08)$ & unemployment & $0.014(2.18)$ \\
\hline married & $0.002(1.89)$ & \multicolumn{2}{|c|}{$\begin{array}{l}\text { time effects omitted } \\
\text { Heteroskedasticity in the inefficiency function }\end{array}$} \\
\hline $\ln$ (income) & $0.027(20.38)$ & Intercept & $-3.212(-0.36)$ \\
\hline training & $0.002(1.46)$ & $\ln (g p)$ & $0.121(0.51)$ \\
\hline unemployed & $0.006(3.33)$ & In(specialists) & $1.022(5.77)$ \\
\hline part time & $0.002(0.35)$ & In(beds) & $0.182(1.01)$ \\
\hline edu1 & $-0.026(-12.31)$ & $\ln \left(\mathrm{gp}^{*}\right)$ & $-0.713(-0.92)$ \\
\hline edu2 & $-0.009(-6.63)$ & In(specialists*) & $0.279(0.28)$ \\
\hline edu3 & $-0.011(-6.14)$ & $\ln \left(\right.$ beds $\left.^{*}\right)$ & $0.038(0.06)$ \\
\hline 2004 & $0.005(1.70)$ & $\ln ($ gdpp.c.) & $-0.486(-2.60)$ \\
\hline 2006 & $0.010(3.61)$ & education & $-0.023(-5.95)$ \\
\hline 2008 & $0.007(2.68)$ & age65 & $-0.073(-4.64)$ \\
\hline 2010 & $0.005(1.76)$ & unemployment & $-0.014(-1.15)$ \\
\hline 2012 & $-0.001(-0.16)$ & \multicolumn{2}{|c|}{ time effects omitted } \\
\hline $\mathrm{Cv}$ & $-5.702(-161.07)$ & - & - \\
\hline$\omega$ & 0.0578 & - & - \\
\hline Log-likelihood & 27761.9 & - & - \\
\hline $\mathrm{AIC}$ & -55409.81 & - & - \\
\hline No of observations & 45054 & - & - \\
\hline
\end{tabular}

and a better understanding of medical treatments $[48,68,69]$. In comparison with a full-time employed individual, we diagnose a positive association of HRQoL with working part-time, being not employed as well as being in training, although the latter two effects lack significance. This positive relationship possibly captures effects of more leisure time for part-time employed persons and higher levels of stress for individuals working in full-time employment.

\section{End Notes}

Although the data structure might call for the consideration of individual effects, we opt for a pooled model reducing both the complexity of the nonlinear SFA model and computational burdens. This is of special relevance for processing SOEP data that comprise thousands of individuals such that the inclusion of individual effects would inflate the number of model parameters $[32,33]$. Furthermore, we consider very small $\mathrm{T}$ cases for some individuals. Additionally, the data exhibits considerable variation between individuals while the variation within crosssectional units is weaker in relative terms (Table 1). Hence, this leads to considerable efficiency losses in the estimation of fixed effects models [34].

${ }^{2}$ Common SFA models apply under the implicit assumption of a monotonic relationship between inefficiency and its determinants. By allowing both moments to depend on covariates, the exogenous determinants might affect inefficiency both negatively and positively. Appendix B provides a detailed derivation of non-monotonic covariate effects (see also Lai and Huang (2010) for a model comparison).

${ }^{3}$ In order to use the full set of health information we restrict our analysis to the SOEP waves 2004, 2006, 2008, 2010, 2012 and 2014.

4‘Bundesinstitut für Bau-, Stadt- und Raumforschung'.

${ }^{5}$ Germany consists of 96 RORs which are artificially created for statistical reasons. However, they are closely related to the European NUTS-2 regions ('Nomenclature des unités territoriales statistiques').

6 To obtain regionally representative statistics individual observations are subjected to a weighting scheme provided by the SOEP (Kroh et al., 2015).

${ }^{7}$ The BMI is an indicator of obesity. It is calculated as the bodyweight in kilograms divided by the squared height in meters. Obesity is a commonly accepted burden of health increasing risks of, e.g., diabetes, high blood pressure and 
asthma (Mokdad et al., 2003). The current recommendations classify a BMI above 25 and 30 to indicate overweight and obesity, respectively (WHO Expert Consultation, 2004).

${ }^{8}$ Employees are generally obliged to participate in the Statutory Health Insurance (SHI) with universal coverage and income related contributions (Hullegie and Klein, 2010). For individuals above a certain threshold (e.g. 59400 Euros in 2018 (BMAS, 2017)) the SHI is voluntary. Those individuals may opt for a private health insurance.

${ }^{9}$ To account for the household's purchasing power we calculate the equivalised household net income based on the definition of the OECD and divide the monthly net household income by the square root of the number of household members (OECD, 2013).

${ }^{10}$ International Standard Classification of Education.

${ }^{11}$ Herwartz and Schley (2018) for details on the implementation of the Vuong test.

${ }^{12}$ For instance, a health conscious behaviour, like a healthy diet and non-smoking, relates to an improved HRQoL, while the (intensive) utilisation of health care services indicates lower well-being at the individual level. Furthermore, a higher socioeconomic status is likely associated with better HRQoL.

${ }^{13} \mathrm{We}$ estimate in total six specifications of the SFA model in (1)-(4) to which we refer as Model I to Model VI. For all models we assume that the mean of the truncated normal distribution of inefficiency depends on regional characteristics. We estimate Models I, II, V and VI on ROR level and Models III and IV on the level of the federal states. By assumption, in Models I and III the variance of the inefficiency is constant for all regions $\left(\sigma_{\mathrm{jt}}^{2}=\sigma^{2}\right)$. In Models II and IV we condition $\sigma_{j \mathrm{j}}^{2}$ on regional characteristics. Model $\mathrm{V}$ and VI include spatially lagged variables for the medical infrastructure in the specification of $\mu_{\mathrm{jt}}$ (Model V) as well as $\mu_{\mathrm{jt}}$ and $\sigma_{\mathrm{jt}}{ }^{2}$ (Model VI). We base the discussion of inferential results on Model VI as it obtains the lowest AIC statistic. The estimated coefficients attached to the production parameters are robust for all model specifications. Detailed estimation results for all models are available from the authors upon request.

${ }^{14}$ Battese and Coelli (1988) define the efficiency scores as $\mathrm{E}\left(\exp \left(-\mathrm{u}_{\mathrm{it}} \mid \varepsilon_{\mathrm{it}}\right)\right)$, where $\varepsilon_{\mathrm{it}}$ is the composite error term of (1), i.e. $\varepsilon_{\mathrm{it}}=\mathrm{v}_{\mathrm{it}}-\mathrm{u}_{\mathrm{it}}$.

${ }^{15} \mathrm{As} \partial(\mathrm{E}(\ln \mathrm{y})) / \partial \mathrm{z}^{\mathrm{r}}=-\partial(\mathrm{E}(\mathrm{u})) / \partial \mathrm{z}^{\mathrm{r}}$, where $\mathrm{z}^{\mathrm{r}}$ is the rth variable in $\mathrm{z}$, one can translate the marginal effect on inefficiency to a direct effect on HRQoL (Wang, 2002).

${ }^{16}$ For instance, Fisher and Wennberg (2003) show that mortality rates are higher in regions with a greater supply of medical services. Mortality from heart attack was, for instance, 5.2\% higher in regions with a high level of medical expenditure (Wennberg, 2005).

${ }^{17}$ Based on data of the morbidity-oriented risk structure compensation ('morbiditätsorientierter Risikostrukturausgleich') for 2008-2009 we classify the regions as either having a morbidity profile above or below the German average. The data was provided by the German 'Bundesversicherungsamt' and classifies the German districts as either having a morbidity above or below the country wide average. As corresponding data is not available at the ROR level, we classify RORs according to the average district values within each region.

${ }^{18}$ All regions in East German have a high morbidity profile.

\section{References}

1. OECD. Fiscal Sustainability of Health Systems: Bridging Health and Finance Perspectives. Paris: Publishing.2015.

2. Porter ME, Teisberg EO. Redefining Health Care: Creating Value-based Competition on Results. Boston: Harvard Business Press.2006.

3. Porter ME. A strategy for health care reform-Toward a value-based system. New Eng J Med.2009;361(2): 109-12.

4. Han PK, Klein WM, Arora NK. Varieties of uncertainty in health care: A conceptual taxonomy. Med Dec Making.2011;31(6): 828-38.

5. McNeil BJ. Hidden barriers to improvement in the quality of care. New Eng J Med.2001; 345(22): 1612-20.

6. Herr A. Cost and technical efficiency of German hospitals: Does ownership matter? Health Econ.2008; 17(9):, 1057-71.

7. Herwartz H, Strumann C. Hospital efficiency under prospective reimbursement schemes: An empirical assessment for the case of Germany. Eur J Health Econ.2014; 15(2): 175-86.

8. Varabyova Y, Schreyögg J. International comparisons of the technical efficiency of the hospital sector: Panel data analysis of OECD countries using parametric and nonparametric approaches. Health Policy.2013; 112(1-2): 70-9.

9. Luasa SN, Dineen D, Zieba M. Technical and scale efficiency in public and private Irish nursing homes-a bootstrap DEA approach. Health Care Management Sci.2016; 1-22.

10. Mutter RL, Greene WH, Spector W, et 1. Investigating the impact of endogeneity on inefficiency estimates in the application of stochastic frontier analysis to nursing homes. J Prod Anal.2013; 39(2): 101-10.

11. Kwietniewski L, Schreyögg J. Efficiency of physician specialist groups. Health Care Manag Sci.2017; 1-17.

12. Bhat VN. Institutional arrangements and efficiency of health care delivery systems. Eur J Health Econom. 2005;6(3): 215-222.

13. Gearhart R. The robustness of cross-country healthcare rankings among homogeneous OECD countries. J App Econ.2016;19(1): 113-43.

14. Greene WH. The econometric approach to efficiency analysis. The Measurement of Productive Efficiency and Productivity Change. Economics.2008; 92-250.

15. Hadad SY, Hadad, Simon-Tuval T. Determinants of healthcare system's efficiency in OECD countries. Eur J Health Econ.2013;14(2): 253-65.

16. Augurzky BT, Kopetsch, Schmitz H. What accounts for the regional differences in the utilisation of hospitals in Germany? Eur J Health Econom.2013;14(4): 615-27. 
Citation: Haschka RE, Herwartz H, Schley K. Individual health-related quality of life and the regional allocation of medical services: Insights from a stochastic health frontier analysis. J Public Health Policy Plann April 2020;4(4):41-56

17. Cullen MR, Cummins C, Fuchs VR. Geographic and racial variation in premature mortality in the U.S.: Analyzing the disparities. PloS one.2012; 7(4): e32930.

18. Felder P, Ziebarth NR. Examining the structure of spatial health effects in Germany using hierarchical Bayes models. Reg Sci Urban Econ.2014;49: 305-20.

19. Kopetsch T, Schmitz H. Regional variation in the utilisation of ambulatory services in Germany. Health Econ.2014;23(12): 1481-92.

20. Rettenmaier AJ, Wang Z. Regional variations in medical spending and utilization: A longitudinal analysis of US Medicare population. Health Econ.2012;21(2): 67-82.

21. Wennberg J, Gittelsohn A. Small area variations in health care delivery: A population-based health information system can guide planning and regulatory decisionmaking. Science.1973;182(4117): 1102-08.

22. Grossman M. On the concept of health capital and the demand for health. J PoliT Economy.1972;80(2): 223-55.

23. Ware J, Kosinski M, Keller S. SF-12: How to Score the SF12 Physical and Mental Health Summary scales (Second ed.). The Health Institute, New England Medical Center, Boston, Massachusetts.1995.

24. Hausman JA. Specification tests in econometrics. Econometrica: J Econ Society.1978; 46(6): 1251-71.

25. Lewbel A. Using heteroscedasticity to identify and estimate mismeasured and endogenous regressor models. JBusiness Econ Stat.2012;30(1): 67-80.

26. Correia I, Veiga P. Geographic distribution of physicians in Portugal. Euro J Health Econ.2010;11(4):383-93.

27. Haschka RE, Schley K, Herwartz H. Provision of health care services and regional diversity in Germany: Insights from a Bayesian health frontier analysis with spatial dependencies. European Journal of Health Economics. 2018;21: 55-71.

28. Latzitis NL, Sundmacher, Busse R. Regionale Unterschiede der Lebenserwartung in Deutschland auf Ebene der Kreise und kreisfreien Städte und deren möglichen Determinanten. Das Gesundheitswesen.2011; 73(04): 217-28.

29. Coelli TJ, Rao DSP, O’Donnell CJ, et al. An Introduction to Efficiency and Productivity Analysis. New York: Springer Science \& Business Media.2005.

30. Wang HJ. Heteroscedasticity and non-monotonic efficiency effects of a stochastic frontier model. J Product Anal.2002;18(3): 241-253.

31. Wang HJ, Schmidt P. One-step and two-step estimation of the effects of exogenous variables on technical efficiency levels. J Product Anal.2002;18(2): 129-44.

32. Cameron AC, Trivedi PK. Microeconometrics: Methods and Applications. Cambridge: Cambridge University Press.2005.

33. Silbersdorff A. Analysing Inequalities in Germany: A Structured Additive Distributional Regression Approach. Wiesbaden: Springer.2017.
34. Cameron AC, Trivedi PK. Microeconometrics Using Stata, Volume 2. College Station: Stata Press.2010.

35. Duschl M, Scholl T, Brenner T, et al. Industry-specific firm growth and agglomeration. Regional Stud. 2015;49(11): $1822-39$.

36. Schupp J, Goebel J, Kroh M, et al. German Socio-Economic Panel Study (SOEP). Jahrbücher.2017;239.

37. Wagner GG, Frick JR, Schupp J. The German SocioEconomic Panel Study (SOEP) - Evolution, Scope and Enhancements. SSRN Electronic J.2007;127: 139-69.

38. Andersen HH, Mühlbacher A, Nübling N. Die SOEPVersion des SF 12 als Instrument gesundheitsökonomischer Analysen. SOEP Res.2007;6: 46.

39. Marcus J. The effect of unemployment on the mental health of spouses - Evidence from plant closures in Germany. J Health Econ.2013;32(3): 546558.

40. Felder S, Tauchmann H. Federal state differentials in the efficiency of health production in Germany: An artifact of spatial dependence? Eur J Health Econ.2013;14(1): 21-39.

41. Herwartz H, Schley K. Improving health care service provision by adapting to regional diversity: An efficiency analysis for the case of Germany. Health Policy.2018;122(3): 293-300.

42. Li X, Lopez RA. Food environment and weight outcomes: A stochastic frontier approach. App Econ.2016;48(47): 4526-37.

43. https://www.gkv-spitzenverband.de/gkv_spitzenverband/ presse/zahlen_und_grafiken/zahlen_und_grafiken.jsp.

44. Schley K. Health care service provision in Europe and regional diversity: A stochastic metafrontier approach. Health Econ Rev.2018; 8(11): 1-11.

45. Chakrabarti A, Rao DN. Efficiency in production of health: A stochastic frontier analysis for Indian states. In A. Tavidze (Ed.), Global Econom. 2007; 105-128.

46. Vuong QH. Likelihood ratio tests for model selection and non-nested hypotheses. Econometrica: J Econom Soc.1989;57(2);:307-33.

47. Bertelsmann Stiftung. Regional Verteilung von Arztsitzen (Arztedichte). In“ Faktencheck Gesundheit.2014.

48. Aka B, Dumont JC. Health, education and economic growth: Testing for long-run relationships and causal links in the United States. App Economet Int Develop. 2008;8(2): $101-10$.

49. Edwards R. ABC of smoking cessation: The problem of tobacco smoking. British Medical J.2004; 328(7433): 217-19.

50. Okosun IS, Choi S, Matamoros T, et al. Obesity is associated with reduced self-rated general health status: Evidence from a representative sample of white, black, and Hispanic Americans. Prev Med.2001;32(5): 429-36.

51. Derose KP, Bahney BW, Lurie N, et al. Immigrants and health care access, quality, and cost. Medical Care Res Re. 2009; 66(4): 355-408. 
52. Derose KP, Escarce JJ, Lurie N. Immigrants and health care: Sources of vulnerability. Health Aff.2009; 26(5): 1258-68.

53. Fletcher JM, Frisvold DE. Higher education and health investments: Does more schooling affect preventive health care use? J Human Cap.2009;3(2): 144-76.

54. Brenner MH, Mooney A. Unemployment and health in the context of economic change. Social Sci Med. 1983;17(16): 1125-38.

55. Gerdtham UG, Johannesson M. A note on the effect of unemployment on mortality. J Health Econ.2003;22(3):50518.

56. Ruhm C. Are recessions good for your health? The Quarterly Journal of Economics 2000;115(2): 617-50.

57. Eibich P, Ziebarth NR. Examining the structure of spatial health effects in Germany using hierarchical Bayes models. Reg Sci Urban Econ.2004;49: 305-320.

58. Wennberg JE. Variation in use of medicare services among regions and selected academic medical centers: Is more better?, Commonwealth. 2005;874: 213-17.

59. Fisher ES, Wennberg JE. Health care quality, geographic variations, and the challenge of supply-sensitive care. Persp Biol Med.2003;46(1): 69-79.

60. O'Riordan M, Dahinden A, Aktürk N, et al. Dealing with uncertainty in general practice: An essential skill for the general practitioner. Primary Care.2011;19(3): 12-7.

61. Anselin L. Unter the hood. Issues in the specification and interpretation of spatial regresson models. Agri Econom. 2002;27(3): 247-67.

62. Raknes G, Morken T, Hunskår S. Travel distance and the utilisation of outof-hours services. Tidsskr Nor Legeforen.2014; 134(22): 2151-6.

63. Mokdad AH, Ford ES, Bowman BA, et al. Prevalence of obesity, diabetes, and obesity-related health risk factors, 2001. Jama.2013;289(1): 76-9.

64. Hullegie P, Klein TJ. The effect of private health insurance on medical care utilization and self-assessed health in Germany. Health Econ.2010; 19(9): 1048-62.

65. Redondo-Sendino A, Guallar-Castillo'n P, Banegas JR, et al. Gender differences in the utilization of health-care services among the older adult population of Spain. BMC Pub Health.2006; 6(155): 1-9.

66. Owens G. Gender differences in health care expenditures, resource utilization, and quality of care. J Managed Care Spec Phar.2008; 14(3): 2-6.

67. Waldron I, Hughes ME, Brooks TL. Marriage protection and marriage selection - Prospective evidence for reciprocal effects of marital status and health. Social Sci Med.1996;43(1): 113-23.

68. Cutler DM, Lleras-Muney A. Education and health: Evaluating theories and evidence. Social Eco Policy Health Policy. 2008;29-60.
69. Marmot M. The influence of income on health: Views of an epidemiologist. Health Affairs.2002; 21(2): 31-46.

70. Battese GE, Coelli TJ. Prediction of firm-level technical efficiencies with a generalized frontier production function and panel data. J Economet. 1988;38(3): 387-99.

71. Bertelsmann Stiftung.egionale Unterschiede in der Gesundheitsversorgung. In Faktencheck Gesundheit.2011.

72. BMAS. Cutler DM, Lleras-Muney A. Education and health: Evaluating theories and evidence. Social Eco Policy Health Policy. 2008;29-60.

73. Verordnung über maßgebende Rechengrößen der Sozialversicherung für 2018: SozialversicherungsRechengrößenverordnung 2018. Teil I Nr. 2017;74: 3778-9.

74. Chaix BJ, Merlo P Chauvin. Comparison of a spatial approach with the multilevel approach for investigating place effects on health: The example of healthcare utilisation in France. J Epidemiol Commu Health. 2009;59(6): 517-26.

75. Florax R, Folmer H. Specification and estimation of spatial linear regression models: Monte Carlo evaluation of pre-test estimators. Reg Science Urban Econ.1992;22(3): 405-32.

76. Greene WH. Distinguishing between heterogeneity and inefficiency: Stochastic frontier analysis of the World Health Organization's panel data on national health care systems. Health Econ.2004; 13(10): 959-80.

77. Hullegie P, Klein TJ. The effect of private health insurance on medical care utilization and self-assessed health in Germany. Health Econ.2010; 19(9): 1048-62.

78. Kroh M, Siegers R, Kühne S. Gewichtung und Integration von Auffrischungsstichproben am Beispiel des Soziooekonomischen Panels (SOEP). Nonres Bias .2015; 409-44.

79. Lai HP, Huang CJ. Likelihood ratio tests for model selection of stochastic frontier models. J Product Anal.2010; 34(1): 3-13.

80. Marmot M. The influence of income on health: Views of an epidemiologist. Health Affairs.2002; 21(2): 31-46.

81. Mokdad AH, Ford ES, Bowman BA, et al. Prevalence of obesity, diabetes, and obesity-related health risk factors, 2001. Jama.2013;289(1): 76-9.

82. OECD. OECD Framework for Statistics on the Distribution of Household Income, Consumption and Wealth. Paris: OECD Publishing.2013.

83. Owens G. Gender differences in health care expenditures, resource utilization, and quality of care. J Managed Care Spec Phar.2008; 14(3): 2-6.

84. Ozegowski, S. and L. Sundmacher (2014). Understanding the gap between need and utilization in outpatient care - the effect of supply-side determinants on regional inequities. Health Policy 114(1), 54-63.

85. Redondo-Sendino A, Guallar-Castillo'n P, Banegas JR, et al. Gender differences in the utilization of health-care services among the older adult population of Spain. BMC Pub Health.2006; 6(155): 1-9. 
Citation: Haschka RE, Herwartz H, Schley K. Individual health-related quality of life and the regional allocation of medical services: Insights from a stochastic health frontier analysis. J Public Health Policy Plann April 2020;4(4):41-56

86. Schneider A, Donnachie E, Tauscher M, et al. Costs of coordinated versus uncoordinated care in Germany: Results of a routine data analysis in Bavaria. BMJ Open.2016;(6): e011621.

87. Schnitzer S, Balke K, Walter A, et al. Do gatekeeping programs increase equality of health care in Germany? A comparison of the health care situation of participants and nonparticipants. Bundesgesundheitsblatt.2011; 54(8): 94250 .

88. Waldron I, Hughes ME, Brooks TL. Marriage protection and marriage selection - Prospective evidence for reciprocal effects of marital status and health. Social Sci Med.1996;43(1): 113-23.
89. WHO Expert Consultation. Appropriate body-mass index for Asian populations and its implications for policy and intervention strategies. Lancet.2012; 363(9403): 157.

\section{*Correspondence to:}

RRouven E Haschka

Chair for Econometrics

University of Göttingen,

Germany

Tel: +495513921390

E-Mail: rouven.haschka@uni-goettingen.de 